\title{
Numerical analysis of buried pipes under field geo-environmental conditions
}

\author{
Ramy Saadeldin ${ }^{1,2^{*}}$, Yafei $\mathrm{Hu}^{3}$ and $\mathrm{Amr} \mathrm{Henni}{ }^{4}$
}

\author{
* Correspondence: \\ Mohamera@uregina.ca \\ ${ }^{1}$ Environmental Systems \\ Engineering, University of Regina, \\ Regina, SK S4S 0A2, Canada \\ ${ }^{2}$ AMEC Environment \& \\ Infrastructure, Regina, SK S4N 4Y1, \\ Canada \\ Full list of author information is \\ available at the end of the article
}

\begin{abstract}
Background: Buried pipes are vital infrastructures and are mostly used to transport energy and other essential commodities. These pipes are generally buried within the top layer of soil deposits, and therefore, are highly affected by different geoenvironmental conditions.

Methods: In this paper, a modeling approach is introduced for the analysis of buried pipelines through real-life scenarios. The model provided reasonable estimates for the elastic deformations of a soil-pipe system under different soil and loading conditions. The model was then used to address the performance of a hypothetical pipeline buried in an unsaturated clay soil. The modeling analysis captured the pipe displacements that occurred due to the change in soil suction associated with changes in the soil moisture content. The soil suction was estimated based on field measurements, and was, then used as an input to the model. The change in volumetric water content in the area studied was found to be as low as $5 \%$, as high as $20 \%$, and corresponded well with the seasonal variation in climate conditions.

Results: Direct correlations between the change in soil moisture content and the resulting pipe displacements were developed.

Conclusions: The results indicated that normalized pipe displacements up to $6 \%$ occurred due to the relative increase in volumetric water content of $20 \%$ representing the change from the field condition to full saturation. The magnitude of pipe displacements increased significantly with the decrease of the pipe depth within the active soil zone.

Keywords: Buried pipe; Unsaturated soil; Elastic deformation; Volumetric water content; Soil suction; Climate conditions
\end{abstract}

\section{Introduction}

Pipeline systems have improved the living standards and have rapidly grown in use over the last 60 years. Buried pipe systems transport vital resources, including water and oil/gas. These pipelines may experience severe working environments and significant deformations during their service life. For example, a total number of 850 water main breaks occur daily in North America, costing over $\$ 3$ billion for annual repairs (Uni-Bell PVC Pipe Association, 2001). These pipelines are normally buried within the top layer of soil deposits, and therefore, are highly affected by different geoenvironmental conditions. Soil conditions are influenced by seasonal climate changes (i.e. wetting and drying cycles, park watering, or any substantial water leakage). These 
changes may induce variations in soil moisture content, which in return cause significant changes in the soil suction, ultimately resulting in extensive soil movements.

The failure of underground pipelines occurs when the applied stresses exceed its structural resiliency. A technically sound design analysis of buried pipes should consider pipe characteristics, internal and external loads, and surrounding conditions such as backfill and side fill materials, installation depth, compaction quality, and road superstructure loads. Unsaturated soil surrounding the pipes may swell as a result of a lasting period of rainfall, which may change loading on the pipes. However, pipeline design guidelines, such as (ASCE, 1984), are based on the assumption that the soil is either dry or fully saturated. Until now, the behavior of unsaturated soils on pipelines is not entirely understood. An understanding of the response of buried pipes to a wide range of geo-environmental conditions can be useful for establishing modified design and construction practices.

The main objective of this research study was to investigate the influence of the most significant design parameters on the performance of buried pipes. Finite element modeling, using the commercial finite element program FlexPDE (PDE Solutions Inc., 2006), was implemented in order to solve the governing stress-strain partial differential equations for a soil-pipe system. The numerical analysis was first performed to predict the elastic deformations occurring due to various backfill materials surrounding the pipe, native soils around the trench, and multiple loading magnitudes. The model was validated using previously developed empirical design equations. The soil upward movement was then simulated in order to draw conclusions regarding the behavior of buried pipes under saturation of surrounding soils.

\section{Background}

\section{Design criteria for buried pipes}

Buried pipes can be classified as either flexible or rigid depending on whether the pipe itself can deform up to $2 \%$ without incurring damage. Rigid pipes, such as reinforced/ non-reinforced concrete, and clay pipes, may experience significant structural cracks if they deflect more than $2 \%$ (Zhao et al., 1998). Flexible pipes have been defined as conduits that can deflect at least $2 \%$ without exhibiting any sign of structural distress such as cracking (Uni-Bell PVC Pipe Association, 2001). Flexible pipes include thermoplastics [i.e., Polyvinyl Chloride (PVC) and High Density Polyethylene (HDPE)], thermosetting, and corrugated steel pipes.

Soil-pipe interaction differs between flexible and rigid pipes. A rigid pipe is responsible for transferring the applied loads to the bedding material. Rigid pipes are generally stiffer than the surrounding soil (Zhao et al., 1998). Flexible pipes support the applied vertical loads through passive pressures induced by the pipe deformation against the surrounding soils (Moser, 1990). Flexible pipes have less inherent stiffness when compared to rigid pipes. Therefore, flexible pipes usually require efficient compaction of the backfill soils during installation. The design of buried pipes in North America began in the early 1900s, initiated mainly by Marston and Anderson (1913). The design of pipes was based on the "ring theory", assuming that the loss in vertical diameter is compensated by an increase of the same magnitude in the horizontal diameter, i.e. the deformed pipe shape is elliptical, as shown in Fig. 1 (Moser, 1990). 


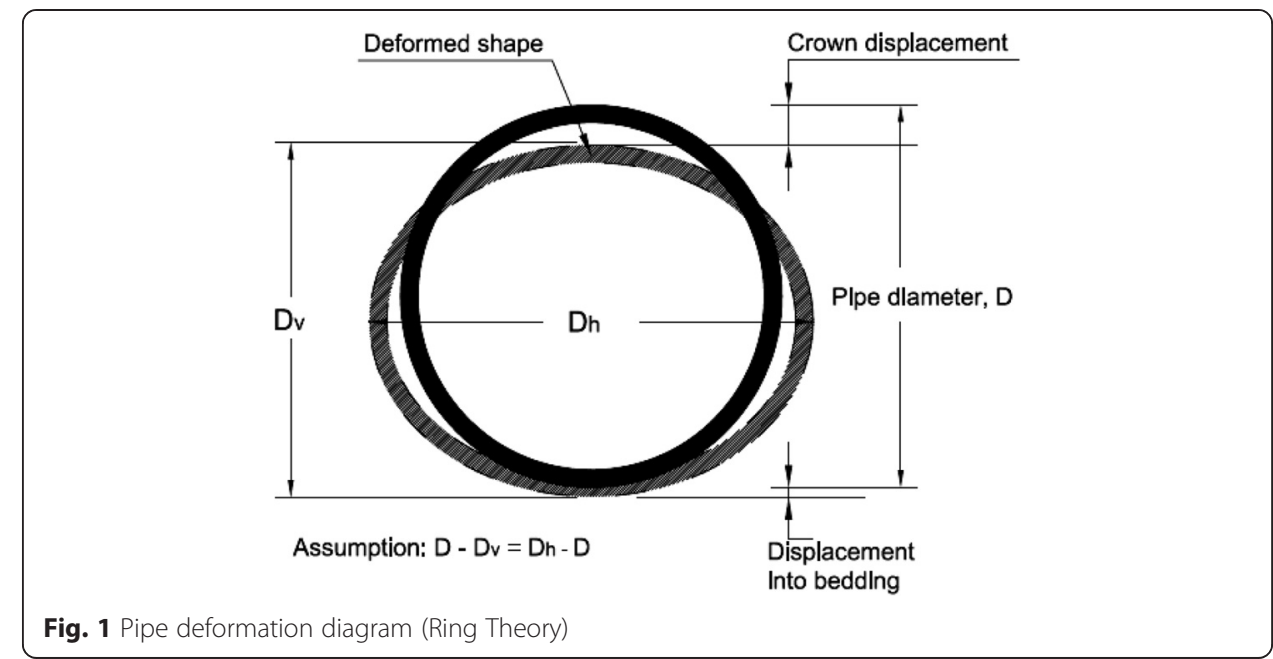

The design criteria of buried PVC pipes incorporate the determination of a sufficient pipe stiffness for mobilizing the backfill soil to resist buckling. Pipe deformation must be limited to eliminate any disruption in the flow or joint leakage (AWWA Manual M23, 2002). General design guidelines for underground PVC pipes can be summarized as follows: (i) limiting the pipe deformation to a maximum of $3 \%$ [i.e. thermoplastic pipe (Zhao et al., 1998)], and 5-7.5 \% [i.e. PVC pipes (Eagle 2009), based on the pipe working pressure]; (ii) preventing buckling of the pipe wall; and (iii) limiting any potential for 'wall crush' that may occur due to vertical loads (soil and live loads) applied directly above the pipe. Spangler (1941) developed the Iowa Formula, as shown in Eq. (1), using previous laboratory testing results. The soil load in the Iowa Formula can be determined using the definition of the soil column load on the underground flexible pipe developed by Marston and Anderson (1913) and shown in Eq. (2).

$$
\begin{aligned}
& \Delta \mathrm{D}=\mathrm{D}_{\mathrm{l}} \mathrm{K}\left[\frac{\mathrm{W}_{\mathrm{c}}}{\frac{\mathrm{E}_{\mathrm{p}} \mathrm{I}}{\mathrm{r}^{3}}+0.061 \mathrm{E}^{\prime}}\right] \\
& \mathrm{W}_{\mathrm{c}}=\mathrm{C}_{\mathrm{d}} \gamma \mathrm{WD}
\end{aligned}
$$

where; $\Delta D$ is the change in pipe diameter $(m), D_{1}$ is a deflection lag factor, $K$ is the bedding constant, $E_{p}$ is the elastic modulus for the pipe material $(\mathrm{kPa})$, I is the moment of inertia of the pipe wall per unit length $\left(\mathrm{m}^{3}\right), \mathrm{E}^{\prime}$ is the modulus of passive resistance of soil $(\mathrm{kPa}), \mathrm{r}$ is the mean pipe radius $(\mathrm{m}), \mathrm{w}_{\mathrm{c}}$ is the soil load on buried pipe $(\mathrm{kN} / \mathrm{m})$, as defined in Eq. (2), $C_{d}$ is load coefficient for the pipe trench, $W$ is the trench width (m), and $\gamma$ is the soil unit weight $\left(\mathrm{kN} / \mathrm{m}^{3}\right)$.

\section{The issue of soil volume change}

Large amounts of water may enter the soil during the rainy seasons and result in excessive soil heave. Conversely, a significant reduction in the water content during the dry seasons may result in the settlement of soils, as shown in Fig. 2 (after Rajeev et al., 2012). The soil deformations were found to be induced on the underground pipes to such magnitudes as to cause them to fail, especially in the case of small diameter pipes 


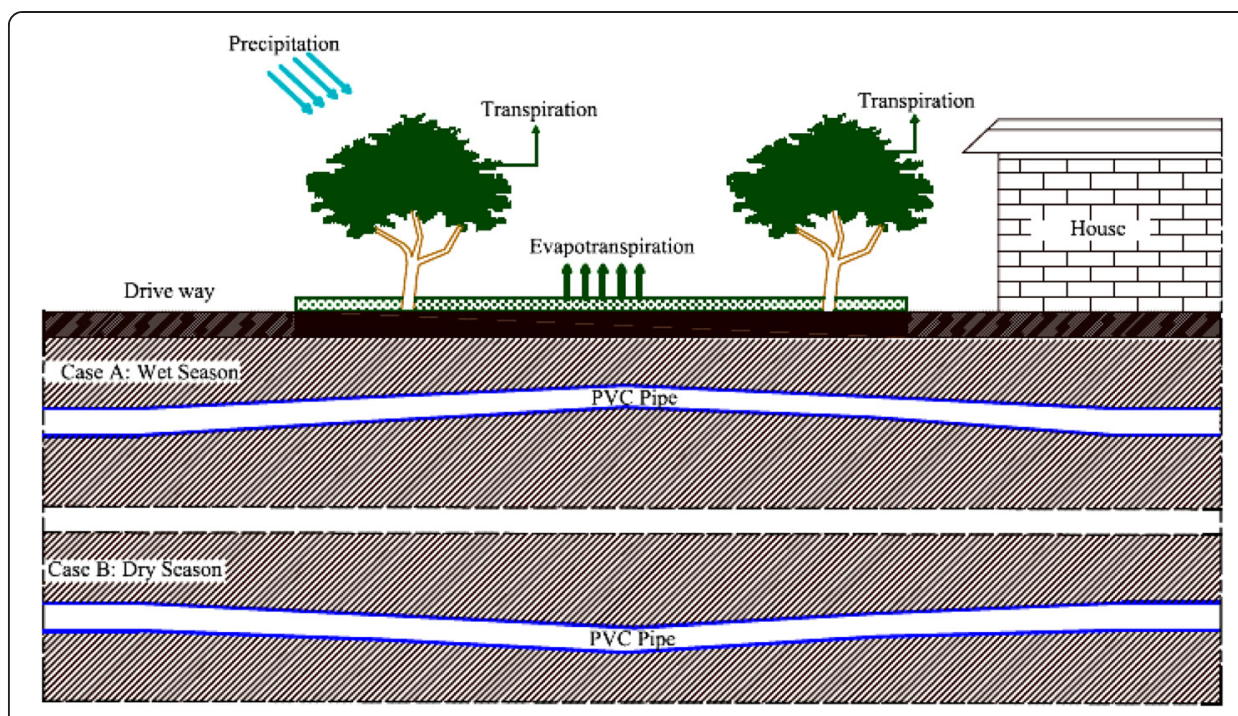

Fig. 2 Schematic diagram of the effect of dry and wet soil conditions on a buried pipeline (after Rajeev et al., 2012)

(i.e. $<200 \mathrm{~mm}$ ). The level of soil stresses on the pipelines depends mainly on the nature of the soil, its natural degree of saturation, and the extent of variation in soil moisture. Morris (1967) and Clark (1971) reported that volume changes in clay were a considerable contributing factor to the high number of water main breaks. Newport (1981) observed that the high breakage rates occurred following very hot and dry summers. In general, a circular break of a pipeline is evidence of bending tensile stress conditions. Bending stresses on underground lines are mainly induced by earth movements.

Gould (2011) investigated the effect of the seasonal variations in climate conditions on the failure rates of Australian water reticulation pipes. The seasonal variation in pipe failure numbers occurred due to excessive ground movements caused by the shrinking and swelling of clay soils. Gould et al. (2009) also concluded that the highest failure rates occurred between December and May. It was clear that the failure rates were strongly associated with the net evaporation and climate conditions. Clayton et al. (2010) analyzed monitoring data over a 2 year period of pipelines installed in London clay. It was reported that notable ground movements, in the order of 3$6 \mathrm{~mm} / \mathrm{m}$ pipe length, were observed in the vertical and horizontal directions. Hudak et al. (1998) studied pipe breakages of cast iron (CI) and PVC pipes buried in the area, each having soils with different shrinkage and swelling potentials. The results showed that the highest density of pipe breaks occurred in areas with the highest plasticity indices, and for 150 and $200 \mathrm{~mm}$ diameter pipes.

Mordak and Wheeler (1988) presented historical data for four asbestos cement (AC) water main assets located in different sites in the United Kingdom. One site was characterized as formed by a clay soil deposit, while the others had sand and gravel deposits. The AC water main, buried within clay soils, was observed to have two failure peaks, corresponding with the long dry periods experienced during two hot summers. Most of the pipe failures occurred during the summer (dry) months. Pipe failures for the three other areas, with sand and gravel soils, occurred randomly throughout the year. Baracos et al. (1955) studied pipe failure data of cast iron (CI) water pipes 
between 1948 and 1953 in the City of Winnipeg (Manitoba, Canada). The monthly circumferential failure rates formed a cyclic pattern that occurred in September and January. A close correlation was derived from the circumferential failure rate pattern and the monthly weather changes, including mean temperatures, precipitation, and depth of snow cover.

\section{Numerical studies in the literature}

The use of numerical modeling allows for assessing the effect of a wide range of variables in a timely and efficient manner. Significant improvements to the capabilities of computer hardware and software have helped improve the numerical modeling techniques. A considerable amount of numerical studies have been performed in order to understand the complex interactions between soil and pipe (Wijewickreme, 2012). Generally, the scale of soil geometry, for most practical applications is large and, therefore, the microscopic properties could be averaged and the soil could be simulated as a continuum. The mechanical behavior of soil can be studied within the framework of the continuum mechanics of solids (Chen, 1990). The continuum soilstructure interaction models, in the form of the stress-strain partial differential equations, were originally developed based on the governing linear elastic continuum relationships. Then, a range of assumptions were made in order to develop the equations in a closed form. Continuum models allowed for the simulation of a wide range of soil parameters (Colasanti and Horvath, 2010). Continuum modeling methods have also resulted in a better understanding of soil-pipe interaction problems (Wijewickreme, 2012).

There are two main modeling approaches in the area of soil-structure interactions for underground pipelines, the Winkler Spring Approach and the Finite Element Analysis. In the Winkler Spring Approach (Winkler, 1867), the pipe is assumed to perform as a thin strip and the soil media is represented by spring elements (Ng, 1994). The springs are generally mounted transverse to the pipe axis in order to simulate the load transfer associated with soil movement acting perpendicular to the longitudinal pipe axis ( $\mathrm{Ng}$, 1994). Winkler's hypothesis is still being used as the main subgrade model in soil-structure interaction applications. Significant improvements have been made to the Winkler Spring Approach in order to reflect the different physical aspects of the soil-structure interaction.

Rajani et al. (1996) presented a Winkler Spring Approach for jointed water mains consisting of cast or ductile iron and PVC pipes. A sensitivity analysis was conducted to identify key variables in the overall behavior of buried water mains. The results demonstrated that temperature changes and the axial soil-pipe reaction modulus had a significant influence on the water main breaks. The Winkler Spring Approach is a conceptual approach for modeling boundary and loading conditions, and often failing to simulate the physical soil behavior in a precise manner (Dutta and Roy, 2002). The Winkler model does not consider the continuity of soil mass, and assumes no soil-pipe interaction between the locations of soil springs along the pipeline (Rajani and Tesfamariam, 2004). The disadvantage of the Winkler model is its simulation of soil pressure in terms of absolute pipe displacement neglecting the impact of rigid body movements of the soil mass (Trickey and Moore, 2007). 
The Finite Element Analysis is an advanced method for numerical solutions where the region of interest is geometrically defined by nodes and represented by "finite" geometric units. A geometric model is solved as a mathematical model and the behavior is described by differential equations and boundary conditions. The performance of flexible pipe with non-uniform soil support was modeled by Zarghamee (1986) as a cylindrical shell embedded in an elastic foundation. It was found that the internal pipe pressure did not mitigate the flexural strains since the invert induced by haunch support was inadequate. Zhan and Ranjani (1997) implemented finite element analysis to evaluate the effect of different trench backfill materials, as well as pipe burial depth, on the performance of buried PVC and ductile pipes. The analysis showed that the use of Controlled Low Strength Material (CLSM) a trench backfill instead of traditional materials, such as sand and clay, resulted in significantly reduced stress on PVC pipe under traffic loading. This was due to the high elastic modulus of CLSM. McGrath (1998) conducted a study on the soil-pipe interaction behavior during construction of flexible and rigid pipes. It was concluded that pipe performance is greatly affected by installation methods and soil properties (i.e. compaction and backfill characteristics).

Trickey and Moore (2007) performed a numerical analysis for pipes of varying stiffness and embedment depth. It was found that the burial depth had little impact on the peak deformation for stiff (rigid) pipes located close to the ground surface. However, for flexible pipe, the peak deformation decreased significantly as embedment depth increased. Barbato et al. (2010) used a linear elastic finite element model to study the effects of geometric and mechanical parameters that characterize the soilstructure interaction developed in a buried pipe located under highways. The study concluded that the soil-pipe interaction system considerably depends not only on the pipe material and stiffness, but also on the geometric parameters defining the pipe trench.

Rajeev and Kodikara (2011) completed a numerical analysis of an experimental pipe, buried in the soil, when subjected to soil movement that was due to an increase in moisture content. The pipe was assumed to behave as a linearly elastic material, while the soil was modeled as a nonlinear material. The study predicted the magnitude of soil movements with the change of water flow. It was also concluded that despite the established influence of expansive soils on the performance of pipelines, the research effort directed at the numerical modeling of the soil-pipe interaction behavior is limited (Rajeev and Kodikara, 2011). Robert and Soga (2013) completed a finite element analysis of unsaturated sandy soils. The results showed that the characterization of soil as an unsaturated state is necessary for pipeline problems to occur. Results also showed that an increase in moisture content resulted in an increase in soil loading on the pipeline.

The preceding review shows that finite element methods can be used effectively to analyze the performance of buried pipes. These studies have provided a database for the behavior and performance of buried pipes in certain field conditions. As reported, the number of studies on the behavior and performance of pipes under various weather conditions is quite limited. Further studies may be needed in order to better understand the overall field performance of buried pipes, and the effects due to changes in unsaturated soil conditions. 


\section{Study area}

The City of Regina continues to face the issue of volume change of the native clay deposits. The geotechnical properties of Regina clay were determined through a field instrumentation program of an underground pipeline conducted by the National Research Council Canada near Emerald Park Road, south of Regina, Saskatchewan. The site experienced high volume of AC pipe breaks. A group of high quality sensors were buried in the native soil (Regina clay) to monitor the soil environment surrounding a new PVC water main. The instruments were properly calibrated to maintain a high quality monitoring of the field after installation ( $\mathrm{Hu}$ and $\mathrm{Vu}, 2011)$. Experimental and field investigations were conducted to identify the soil properties in the area (Vu et al., 2007).

This research is based, mainly, on collected field soil test data to represent soil conditions. The input model parameters were based on laboratory tests conducted on the field soil samples. Table 1 shows a summary of the key geotechnical index properties of Regina clay. The measured water content for the field samples of Regina clay ranged from 23 to $35 \%$. The soil specific gravity, average void ratio, and average dry unit weight were found to be $2.73,0.95$, and $15.40 \mathrm{kN} / \mathrm{m}^{3}$, respectively. Laboratory soil tests indicated that natural water contents were slightly below the plastic limit of the clay. The liquid limit, plastic limit, and plasticity index were found to be in the range of (64-94 \%) and (23-34\%), and (37-66 \%), respectively. The soil Poisson's ratio, $\mu_{\mathrm{s}}$ was assumed to be 0.33 . The field matric suction was found to be in the range of $700 \mathrm{kPa}$ to $3000 \mathrm{kPa}$.

The grain size distribution curve of Regina clay was plotted in Fig. 3. The curve shows that the soil is comprised of about $99.9 \%$ of silt and clay $(\leq 74 \mu \mathrm{m})$, and $0.1 \%$ of sand $(\leq 5 \mathrm{~mm})$. Soil-water characteristic curves of the clay at the test site were developed. Figure 4 shows the soil water characteristic curve (SWCC) of Regina clay predicted using the Fredlund and Xing Fitting of the laboratory measurements of soil suctions.

Figure 5 shows the volumetric water content $(\theta)$ measurements at three levels 0.45 , 2.93, and $4.06 \mathrm{~m}$ at the field site in the clay deposits surrounding the pipe trench. As a general trend, clays at low levels $(2.93 \mathrm{~m}$, and $4.06 \mathrm{~m})$, experienced relatively small variations in volumetric water contents, and were found to be in the range of $\pm 5 \%$. The variation in volumetric water content was related to the seasonal variation in

Table 1 Geotechnical index properties of Regina clay

\begin{tabular}{ll}
\hline Parameter (unit) & Value \\
\hline Specific gravity & 2.73 \\
Average dry density $\left(\mathrm{kN} / \mathrm{m}^{3}\right)$ & 15.40 \\
Average wet density $\left(\mathrm{kN} / \mathrm{m}^{3}\right)$ & 19.87 \\
Natural water content (\%) & $23-35$ \\
Initial void ratio, $e_{0}$ & 0.95 \\
Liquid limit (\%) & $64-94$ \\
Plastic limit (\%) & $23-34$ \\
Plastic index (\%) & $37-66$ \\
Swelling index, $\mathrm{C}_{\mathrm{s}}$ (Consolidation test) & 0.09 \\
Swelling index, $C_{m}$ (SWCC test) & 0.08 \\
\hline
\end{tabular}




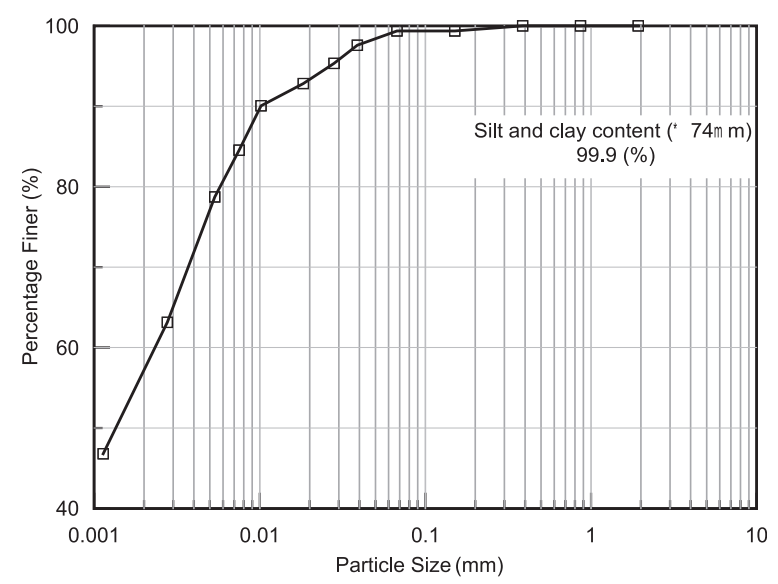

Fig. 3 Grain size distribution of Regina clay

climate conditions, without significant transits during rainfall or snowmelt events. The clay soil at a higher level $(0.45 \mathrm{~m})$ had prominent variations in volumetric water content which corresponded well to the seasonal variation in the climate conditions and the rainfall or snowmelt events. The change in volumetric water content at this level was found to reach a maximum of $20 \%$.

\section{Mathematical formulation}

\section{Governing stress-strain partial differential equations}

The soil-pipe system was modeled as an elastic continuum. The proposed finite element modeling approach was used to account for volume change effects, soil layering, and displacement of the pipe relative to the soil. The main objective of the soil-pipe interaction analysis was to predict the elastic deformations that would occur due to the change of the soil normal stresses and soil moisture content as shown in Fig. 6. The numerical analysis accounted for a wide range of different backfill materials and native soils around the pipes, as well as for multiple loading magnitudes. The elastic

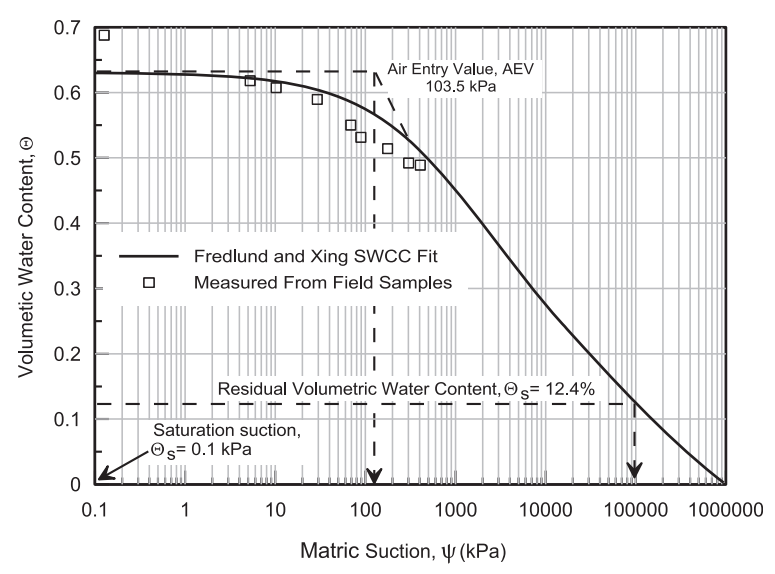

Fig. 4 Soil water characteristic curve (SWCC) of Regina clay 


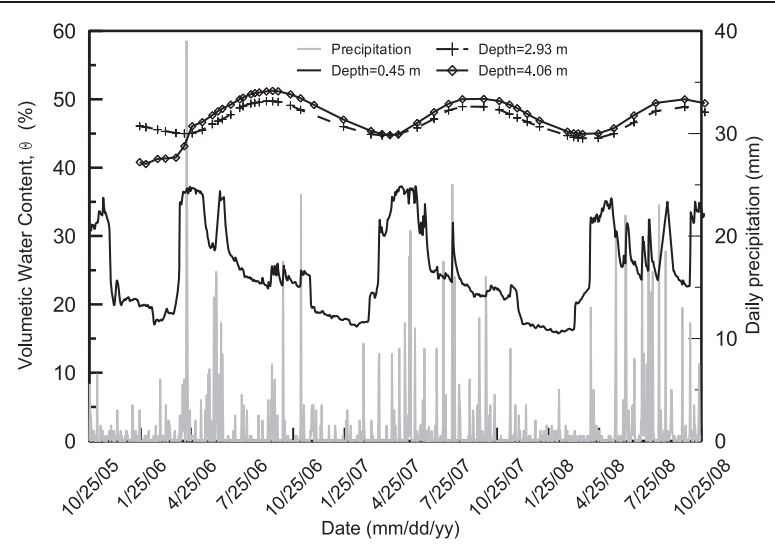

Fig. 5 Volumetric water content versus time in the clay deposit at various levels

continuum solution for buried pipes can be represented by Eq. (3) as suggested by Klar et al. (2004).

$$
[\mathrm{PS}]\{\mathrm{u}\}=\{\mathrm{F}\}
$$

where, [PS] is the stiffness matrix of the pipe, $\{u\}$ is the pipe displacement, and $\{F\}$ is a force vector representing the soil loading.

The constitutive relationships for the modeling of unsaturated soil conditions were formulated as an extension of the saturated soil constitutive equations and utilized two independent measures consisting of the total normal stress $\left(\sigma_{n}\right)$ and soil suction $(\psi)$. Soil deformations occurred due to the change in total soil volume were then defined as the summation of the normal strains in $\mathrm{x}$ and $\mathrm{y}$ directions (Fredlund and Morgenstern, 1976).

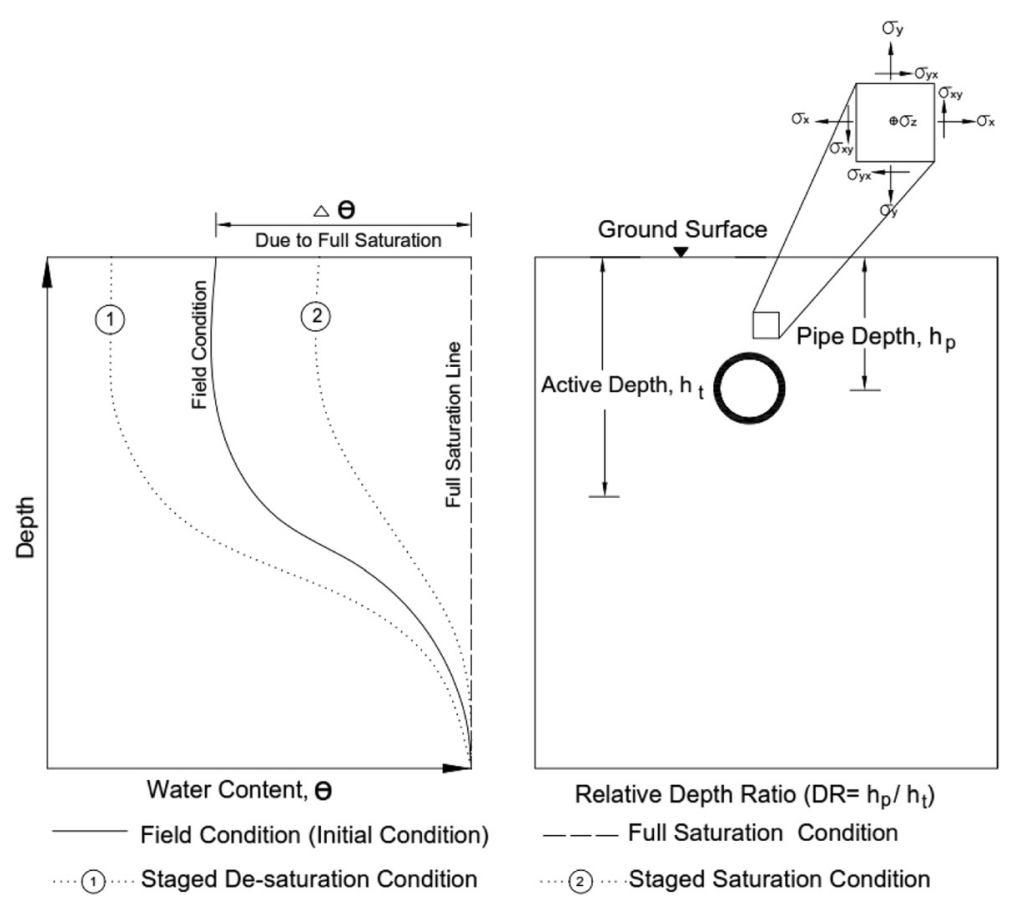

Fig. 6 Theoretical model for the analysis of a buried pipe under unsaturated soil conditions 
The incremental elastic forms of these equations were provided in Eq. (4)-(11) (Fredlund and $\mathrm{Vu}, 2003$ ). The main coefficients of volume change were calculated as a function of the soil matric suction and net normal stress as shown in Fig. 7 (Fredlund and Rahardjo, 1993).

The governing stress-strain equations can be presented in terms of displacements in the $\mathrm{x}$ and $\mathrm{y}$ directions $(u$ and $v)$. The stress-strain relation was assumed to be linear within each stress and strain increment; however, the elasticity parameters, E and $\mathrm{H}$, were allowed to change in magnitude between increments. The equations were obtained based on the following main assumptions: (i) air phase is continuous and remains at atmospheric pressure; (ii) soil is elastic, isotropic, and nonlinear; (iii) pore water is incompressible; (iv) effects of air diffusing through water, air dissolving in the water are negligible; and (v) movement of water vapor is negligible (Vu and Fredlund, 2004).

$$
\begin{aligned}
& \frac{\partial}{\partial x}\left[c_{11} \frac{\partial u}{\partial x}+c_{12} \frac{\partial v}{\partial y}\right]+c_{33} \frac{\partial}{\partial y}\left[\frac{\partial u}{\partial y}+\frac{\partial v}{\partial x}\right]-c_{e} \frac{\partial \psi}{\partial x}+F_{x}=0 \\
& c_{33} \frac{\partial}{\partial x}\left[\frac{\partial u}{\partial y}+\frac{\partial v}{\partial x}\right]+\frac{\partial}{\partial y}\left[c_{12} \frac{\partial u}{\partial x}+c_{22} \frac{\partial v}{\partial y}\right]-c_{e} \frac{\partial \psi}{\partial y}+F_{y}=0 \\
& C_{11}=C_{22}=\frac{\left(1-\mu_{s}\right) E}{\left(1+\mu_{s}\right)\left(1-2 \mu_{s}\right)} \\
& C_{12}=\frac{\mu_{s} E}{\left(1+\mu_{s}\right)\left(1-2 \mu_{s}\right)} \\
& C_{33}=\frac{E}{2\left(1+\mu_{s}\right)} \\
& C_{e}=\frac{E}{\left(1-2 \mu_{s}\right) H} \\
& E=\frac{4.605\left(1+\mu_{s}\right)\left(1-2 \mu_{s}\right)\left(1+e_{0}\right)}{C_{s}} d \sigma
\end{aligned}
$$

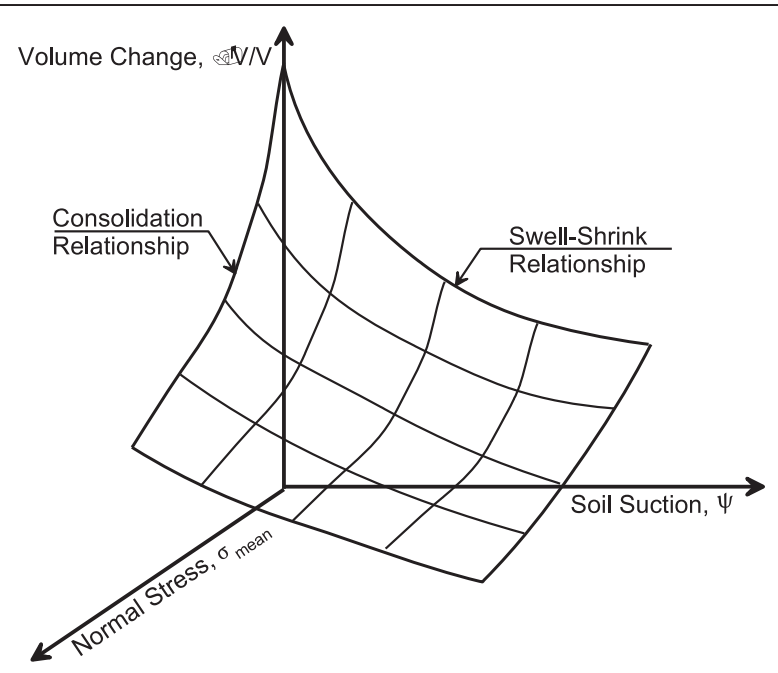

Fig. 7 Volume change constitutive surfaces of an unsaturated swelling soil (Fredlund and Rahardjo, 1993) 


$$
\mathrm{H}=\frac{4.605\left(1+\mu_{\mathrm{s}}\right)\left(1+\mathrm{e}_{0}\right)}{\mathrm{C}_{\mathrm{m}}} \mathrm{d} \psi
$$

where, $\mu_{\mathrm{s}}$ is the Poisson's ratio for the soil, $\mathrm{F}_{\mathrm{x}}$ and $\mathrm{F}_{\mathrm{y}}$ are $\mathrm{x}$ and $\mathrm{y}$ components of the body force vector; $E$ is the elasticity parameter as a function of the net normal stress; $\mathrm{H}$ is the elasticity parameter as a function of the change in matric suction; $\mathrm{C}_{\mathrm{s}}$ and $\mathrm{C}_{\mathrm{m}}$ are swelling indices obtained from net normal stress plane and matric suction plane, respectively; $\mathrm{C}_{\mathrm{e}}, \mathrm{C}_{11}, \mathrm{C}_{12}$, and $\mathrm{C}_{33}$ are the stiffness tensor components as defined by Fredlund and Gitirana (2005); d $\sigma$ is the net normal stress; and $d \psi$ is the change in matric suction.

\section{Modeling overview, geometry, and boundary conditions}

Finite element modeling, using the commercial Finite Element program FlexPDE (PDE Solutions Inc., 2006), was implemented in order to solve the governing partial differential stress-stain equations for underground pipes. FlexPDE is a general partial differential equation solver that uses the finite element method for numerical solution of boundary value problems. Major features of FlexPDE include the following: the capability of solving non-linear partial differential equations of second order or less; flexibility to input nonlinear functions for material properties (e.g. unsaturated soil properties); elimination of the need for manually determining an appropriate mesh; adaptive grid refinement and time step definition; ensuring user pre-determined accuracy; and help in achieving convergence (Pentland and Fredlund, 2001).

A two dimensional soil-pipe model was used to perform load-deformation analysis of a typical underground pipe system that was under different soil and loading conditions as presented in Fig. 8. The soil-pipe system was modeled under plain strain conditions. The material used to fill the pipe trench was subdivided into three different layers (bedding, backfill, and cover). The natural soil surrounding the trench, the soil in the trench, and the road pavement structures were modeled as separate layers. A parametric study was initially conducted to evaluate the most significant design parameters as reported in Saadeldin et al. (2013a). The appropriate boundary conditions were applied along the borders of the finite element model. The bottom of the model was defined

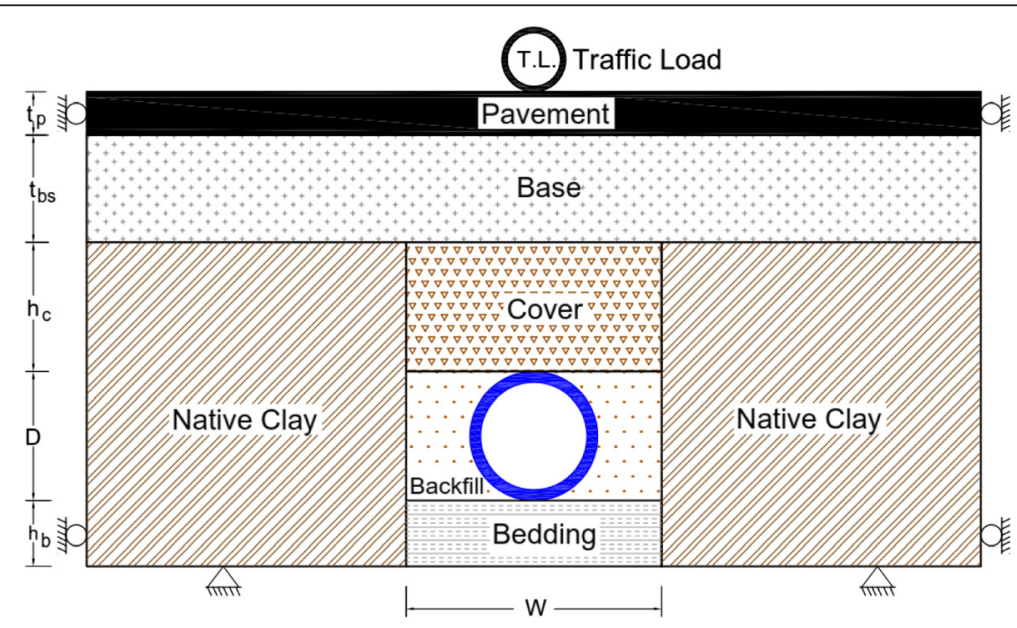

Fig. 8 Model geometry for the load-deformation analysis 
as a fixed boundary, where the horizontal and vertical displacements were set equal to zero. However, the vertical sides of the model had only a horizontal displacement equal to zero. Loads specified for the analysis include the in-situ soil pressure in the soil profile, and the assumed traffic loads. The traffic loads were applied statically in the model as concentrated (point) loads as a simulation of the wheel loads. The main input parameters of the sensitivity analysis for the load-deformation analysis are summarized in Table 2.

A second model was developed to solve the soil-structure interaction equations under unsaturated soil conditions (Saadeldin et al., 2013b). Figure 9 presents the geometry and boundary conditions used for the 2-dimensional analysis. The soil mass was divided into two main zones. The first zone (inactive zone) is covered with pavement, which significantly reduces the infiltration of precipitation into the zone, whereas the second zone (active zone) is directly subjected to various weather conditions. The soil under the pavement was assumed to have a negligible matric suction change, a result of limited vertical moisture flows. Free movement in the vertical direction was allowed at the top boundary and horizontal movements of both the left and right sides were fixed. The lower boundary was fixed in both directions. The boundary conditions of the pipelines were defined independently of the side boundaries of the model to represent different end restraints. The pipeline had a nominal diameter of $0.15 \mathrm{~m}$, a total length of $6.5 \mathrm{~m}$, and a length of $4.0 \mathrm{~m}$ in the active zone. The pipe depth within the active zone was presented by a relative depth ratio (DR) which was equal to the pipe depth divided by the total active depth of the soil.

Change in soil suction occurs within the soil active depth as a result of the change of the climate conditions. The field natural water content of Regina clay was found to be around $40 \%$, close to the plastic limit. The field soil suction was measured to be around $2000 \mathrm{kPa}$. When water enters the soil, the soil suction gradually decreases. To account for this decrease in soil suction for modeling purposes, a set of soil suction values (i.e. 1000, 500, 180, and $38 \mathrm{kPa}$ ) were modeled. This corresponds to the approximate increase of volumetric water content $(\Delta \theta)$ of $5,10,15$, and $20 \%$. The soil suction variation in the active zone was assumed to extend to the whole active depth. The main input parameters of the unsaturated soil-pipe model are summarized in Table 3.

Table 2 Summary of the main parameters for the load-deformation modeling analysis

\begin{tabular}{ll}
\hline Parameter (unit) & Value \\
\hline Pipe diameter to thickness ratio, D/t & 10 \\
Soil bedding thickness, $h_{p}(m)$ & 0.15 \\
Pavement thickness, $t_{p}(m)$ & 0.1 \\
Sub-base thickness, $t_{b s}(m)$ & 0.25 \\
Poisson's ratio of pipe, $\mu_{p}$ & $0.2-0.4$ \\
Poisson's ratio of clay, $\mu_{s}$ & 0.3 \\
Modulus of elasticity of clay, $E_{s}(\mathrm{kPa})$ & $9500-47,500$ \\
Modulus of elasticity of pipe, $E_{p}(G P a)$ & $2.8-280$ \\
Pipe diameter, $D(m)$ & $0.15-0.6$ \\
Cover thickness, $h_{c}(m)$ & $0.3-2.0$ \\
Traffic load, $T . L .(k N)$ & $0.0-100$ \\
\hline
\end{tabular}




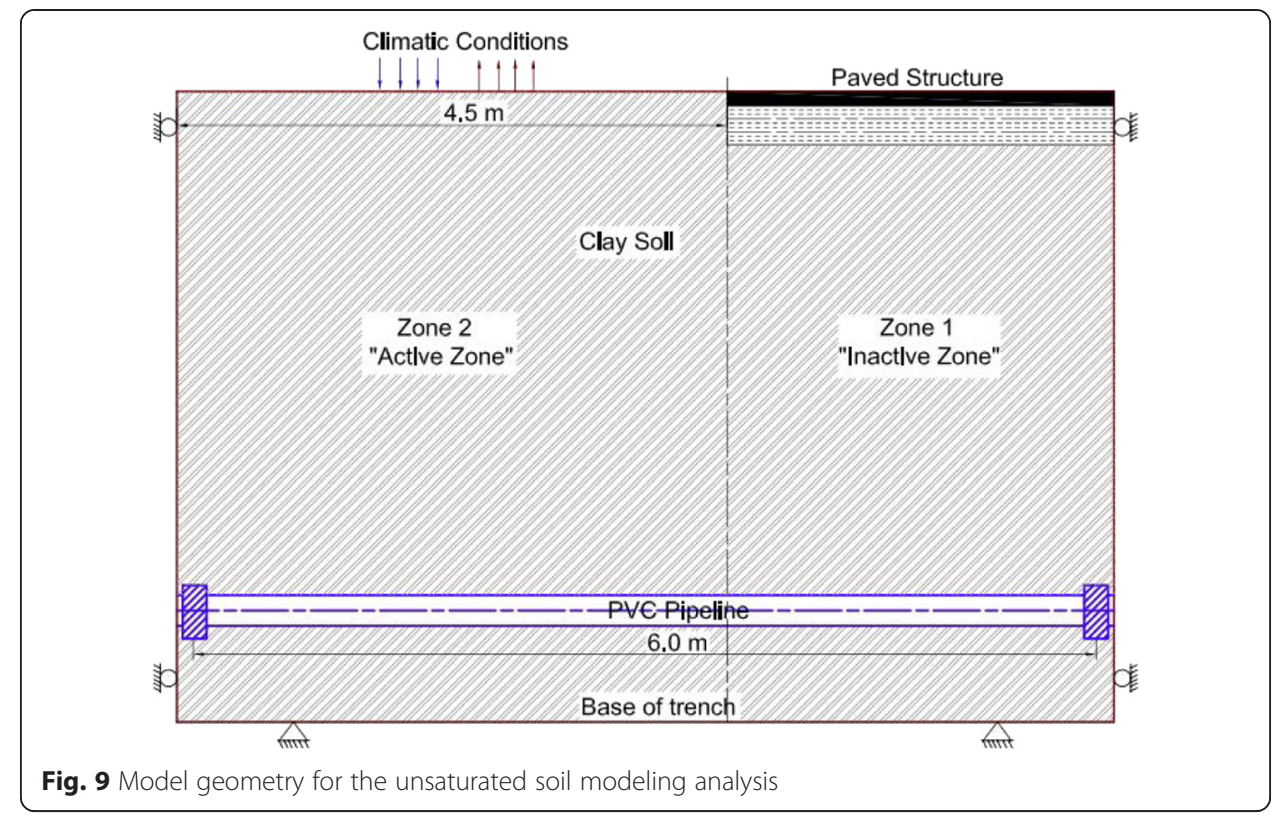

\section{Numerical modeling versus analytical results}

The results of Spangler's empirical equation were determined according to Eq. (1) without considering the applied surface traffic load or pavement structure. The soil load $\left(\mathrm{w}_{\mathrm{c}}\right)$ in Spangler's equation was obtained in accordance with Eq. (2). In addition, as defined by Moser (1990), the load coefficient $\left(C_{d}\right)$ was determined to be 1.55 and 0.84 for a trench width of two and six times the pipe diameter, respectively. It was observed that the results of the numerical analysis matched the analytical results obtained by Spangler's equation for wider trench configuration. These results and similarities resulted in higher deformations for trenches of less width (i.e. twice the pipe diameter), as shown in Fig. 10. It is important to note that Spangler's equation uses a distinct elastic modulus of the soil to represent the backfill soil. However, the numerical simulation is capable of fully considering the variation in elastic properties between the backfill soil and the native soil surrounding the pipe trench.

The results of the cumulative swelling movement occurring at the ground surface were validated against the results determined by Eq. (12) suggested by Fredlund and Rahardjo (1993).

$$
\mathrm{S}_{\mathrm{h}}=\frac{\mathrm{C}_{\mathrm{s}}}{\left(1+\mathrm{e}_{0}\right)} \mathrm{h}_{1} \log \left(\frac{\mathrm{P}_{\mathrm{f}}}{\mathrm{P}_{0}}\right)
$$

where, $\mathrm{S}_{\mathrm{h}}$ is the surface heave $(\mathrm{m}) ; \mathrm{P}_{\mathrm{f}}$ is the final stress state in the soil layer $(\mathrm{kPa}) ; \mathrm{P}_{\mathrm{o}}$ is

Table 3 Summary of the main parameters for the unsaturated soil-pipe modeling analysis

\begin{tabular}{lc}
\hline Property (unit) & Value \\
\hline Initial soil suction, $\psi_{\mathrm{i}}(\mathrm{kPa})$ & 2000 \\
Change in volumetric water content, $\Delta \theta(\%)$ & $5-20$ \\
Relative depth ratio, DR & $0.5-0.9$ \\
Modulus of elasticity of pipe, $\mathrm{E}_{\mathrm{p}}(\mathrm{GPa})$ & $2.8-280$
\end{tabular}




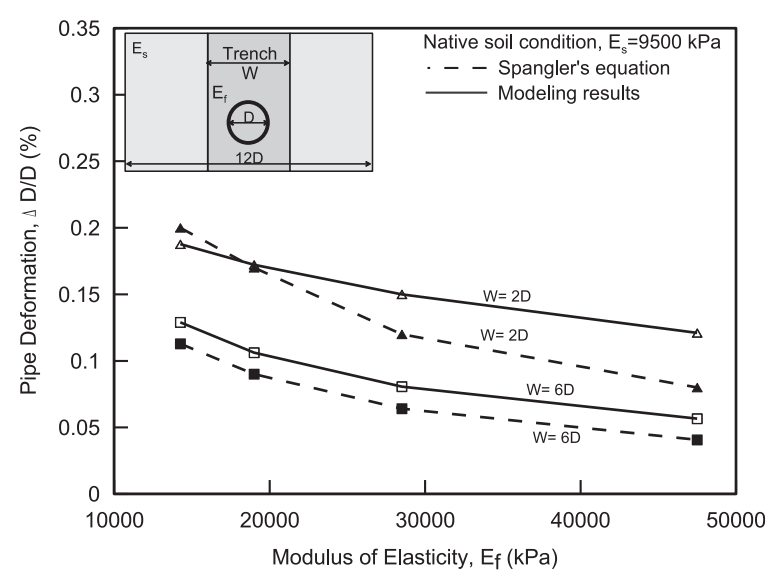

Fig. 10 Effect of the trench width on the maximum pipe deformations

the initial stress state in the soil layer $(\mathrm{kPa}) ; \mathrm{h}_{\mathrm{l}}$ is the layer thickness $(\mathrm{m}) ; \mathrm{C}_{\mathrm{s}}$ is the swelling index; and $\mathrm{e}_{0}$ is the initial void ratio.

The initial state of stress was defined as the measured swelling pressure which is a function of the soil depth. The soil profile was divided into fifteen layers. The average swelling pressure of Regina clay was found to be as low as $80 \mathrm{kPa}$ and as high as 200 $\mathrm{kPa}$ within an active soil depth. The final state of soil stress was equal to the net effective overburden pressure. The resulting cumulative surface heave at the ground surface ranged from 60 to $115 \mathrm{~mm}$. The maximum surface heave resulting from the modeling analysis was found to be $80 \mathrm{~mm}$, which falls within the range of the estimated values.

\section{Results and discussion}

\section{Load-deformation analysis}

The performance of pipelines is influenced by the trench backfill, and the natural soil surrounding the trench. The surrounding backfill material provides considerable support for underground flexible pipelines. It is generally understood that the narrower the trench, the lighter the load applied on the pipe. However, in the case of flexible pipes, the pipe tends to rely heavily on the surrounding soil to carry the applied loads. A flexible pipe principally derives its resistance strength from the passive pressures induced by the relative movement of the sides of the pipe against the surrounding soil (Moser, 1990).

The performance of buried pipes was analyzed under different backfill material conditions. Figure 11 shows the maximum pipe deformations $(\Delta D / D)$ due to the increase in soil elasticity ratio between the backfill soil in the trench and the native soil $\left(E_{f} / E_{s}\right)$. Two main cases were studied, including, trenches with a width of two and six times the pipe diameter. When the backfill soil strength was less than the native soil $\left(E_{f} / E_{s}<1\right)$, the rate of increase in pipe deformation for the wide trench was much higher than in the case of the narrow trench. Conversely, when the backfill soil strength is higher than the native soil $\left(E_{\mathrm{f}} / \mathrm{E}_{\mathrm{s}}>1\right)$, the pipe deformation with a wide trench was lower than in the case of a narrow trench.

In the case of a trench width of two times the pipe diameter, the resulting reduction in the maximum pipe deformation was up to about $35 \%$ with an increase in soil elasticity factor $\left(\mathrm{E}_{\mathrm{f}} / \mathrm{E}_{\mathrm{s}}\right)$ to 5 . However, increasing $\left(\mathrm{E}_{\mathrm{f}} / \mathrm{E}_{\mathrm{s}}\right)$ to 5 in a trench width of six times 


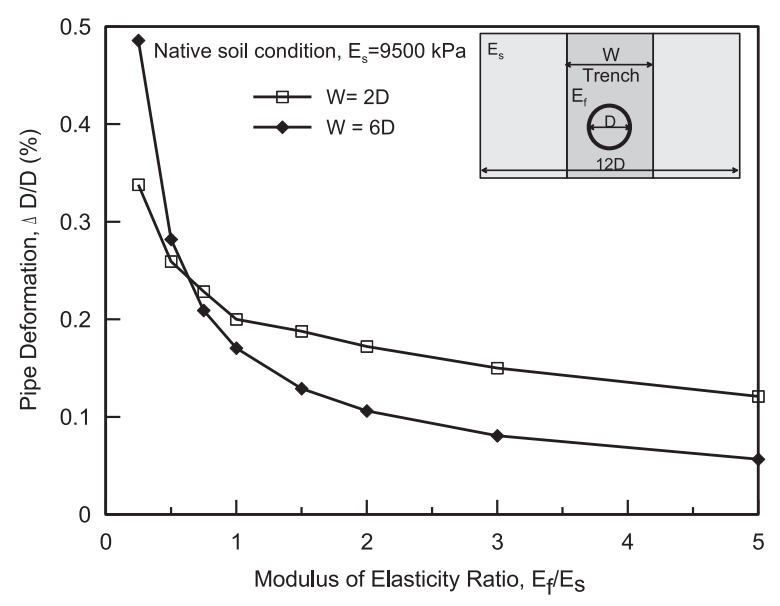

Fig. 11 Effect of the backfill modulus of elasticity on the pipe deformations

the pipe diameter resulted in a reduction in the pipe deformation up to about $60 \%$. Higher backfill strengths were found to have a considerable contribution on the behavior of flexible pipes. This response is a result of the better confinement provided to the sides of the pipe with filling material that is stiffer than the natural soil surrounding the trench. These results confirm that flexible pipes mainly derive their ability to resist loads from the lateral pressure of the soil along the sides of the pipes.

Figure 12 shows the influence of the soil cover thickness $\left(h_{c}\right)$ on pipe deformation occurring under different surface traffic load magnitudes (i.e., 0, 10, 25, 50, 75, and $100 \mathrm{kN})$. As a general trend, deeper installation depths increased the effect of soil load and decreased the effect of the surface load on underground pipelines. However, pipe deformations were found not to monotonically increase with the increase in soil cover under high surface loads. The pipe diameter (D) and elastic modulus $\left(E_{p}\right)$ are among the other factors affecting the maximum deformation magnitude. Pipe deformation increased with the decrease in pipe diameter and elastic modulus as shown in Fig. 13. It was generally observed that PVC pipes are subjected to

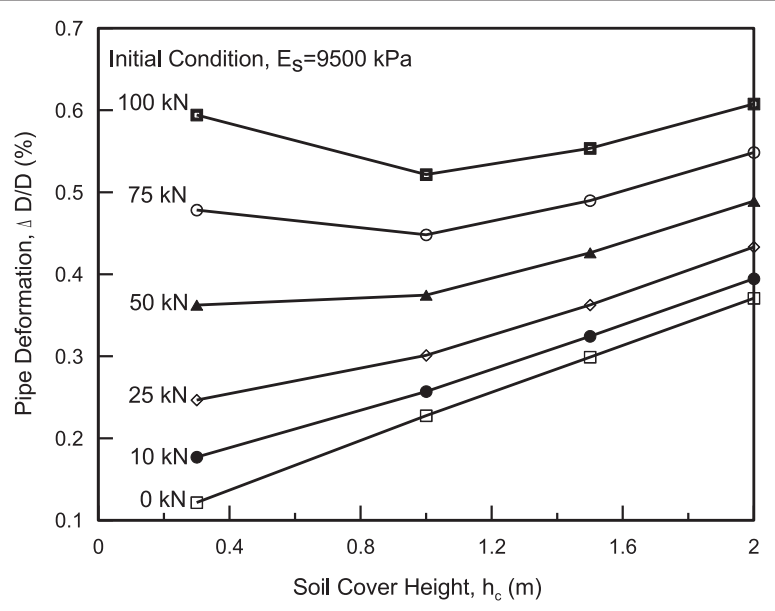

Fig. 12 Effect of the soil cover thickness and loading conditions on the pipe deformations 


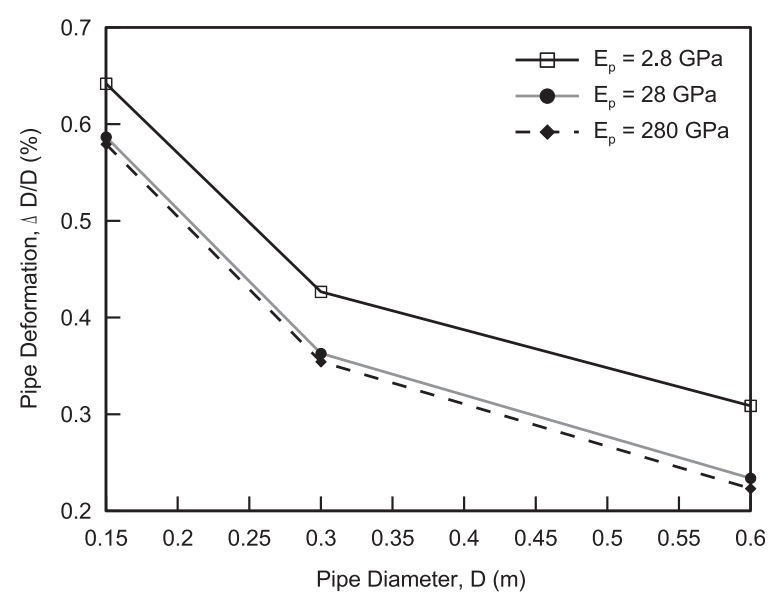

Fig. 13 Effect of the pipe diameter on the pipe deformations

higher pipe deformations than rigid pipes due to their low elastic modulus as compared to rigid pipes. The rate of increase in pipe deformation with the decrease in pipe diameter was also found to be different between $0.6-0.3 \mathrm{~m}$ and $0.3-0.15 \mathrm{~m}$.

\section{Soil-pipe analysis under different unsaturated soil conditions}

Figure 14 presents the maximum pipe displacements predicted at the pipe surface for different pipe depth ratios of $0.5,0.67$, and 0.9 . When the pipeline was installed at a shallower depth, it was subjected to higher displacement under the same variation of water content and degree of saturation. The resulting pipe displacements increased from 6 to $28 \%$ with the decrease of the relative depth ratio (DR) from 0.9 to 0.5 . The magnitude of upward soil movement was mainly affected by the change in soil elasticity as a result of the increase in the total normal stress with depth.

Figures 15 and 16 show the normalized pipe displacement (pipe displacement/pipe diameter, or $d / D)$ profiles found at the top pipe surface along the pipeline length $(X / L)$ at different water content variations in the soil active zone. These two figures were

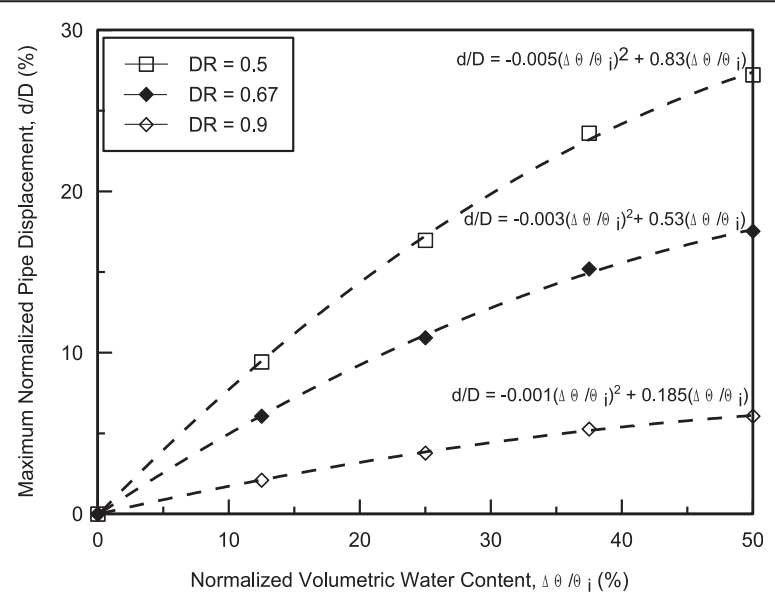

Fig. 14 The maximum displacements versus the variation in soil suction 


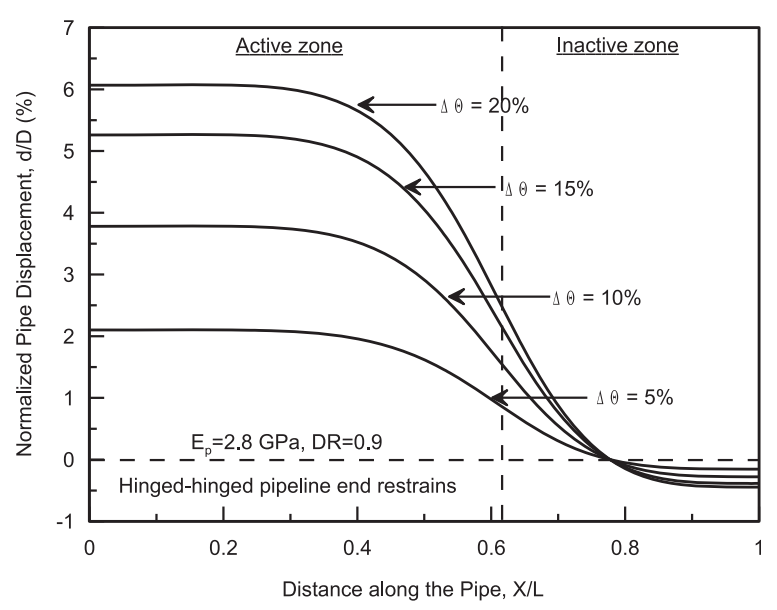

Fig. 15 Pipe displacements due to the variation in soil moisture content under hinged end restraints

obtained for hinged and fixed end constraint conditions. In the case of hinged end restraints, the maximum vertical displacement occurred at the left edge of the pipe in the active zone, and it decreased along the length of the pipe. On the other hand, for fixed end restraints, the maximum vertical displacement occurred around the approximate center of the active zone and decreased near the two edges of the pipeline.

The difference in the maximum normalized vertical displacement between the hinged and fixed end restraint cases was found to be quite small (less than $0.2 \%$ ) due to the low modulus of elasticity for PVC pipes. For the studied cases, the maximum normalized pipe displacement was found to be about $6 \%$, corresponding to the relative increase in volumetric water content, about $20 \%$ (approximately corresponds to the change from the field condition to full saturation). The maximum pipe displacements were approximately $2.1,3.7$, and $5.3 \%$, with a relative increase in volumetric water content of 5,10 , and $15 \%$ in the active zone, respectively.

Figures 17 and 18 show the distribution of normalized pipe displacement along the pipe for various properties of pipe materials. It was observed that the end restraints of flexible pipes did not have an influence on the maximum

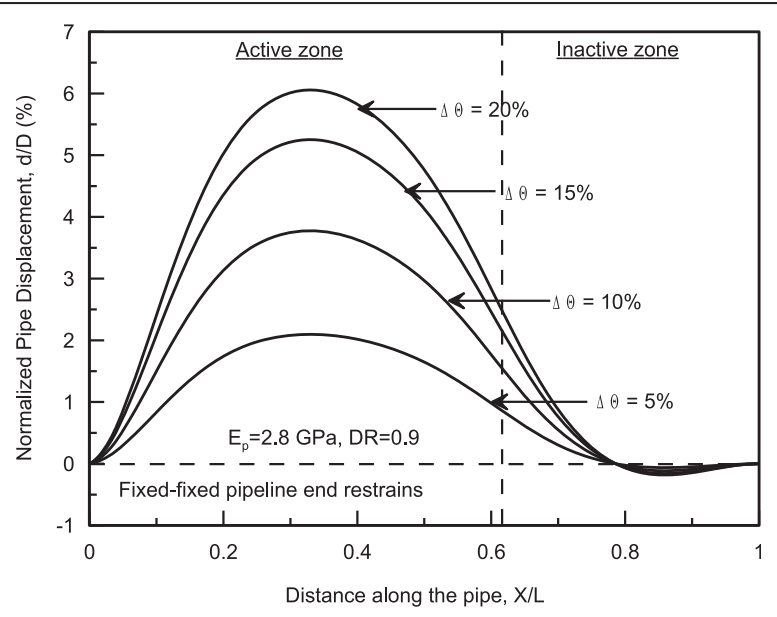

Fig. 16 Pipe displacements due to the variation in the soil moisture content under fixed end restraints 


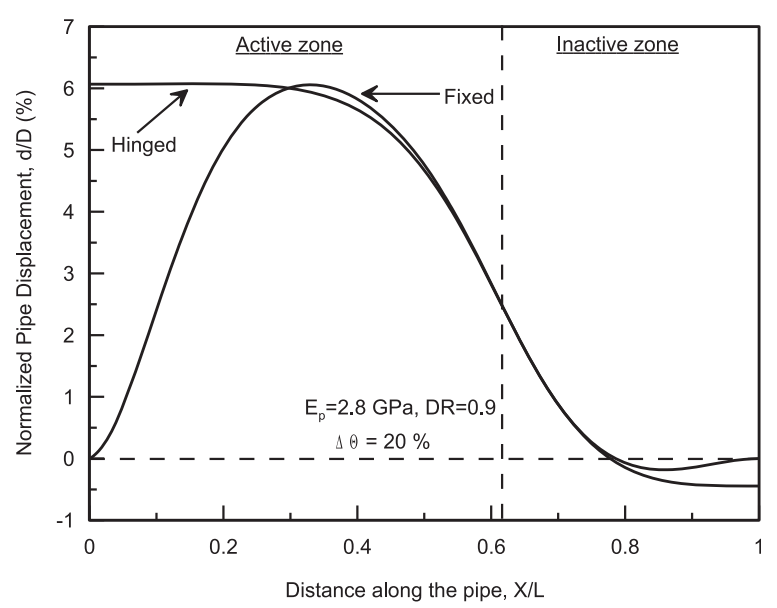

Fig. 17 Pipe displacements in case of both hinged and fixed end restraints for a low elastic modulus magnitude (i.e. PVC pipe)

displacement magnitudes of the pipe (d/D), however it affected the distribution of displacement along the pipeline. On the other hand, the end pipeline restraints showed a considerable effect on rigid pipes. The maximum normalized pipe displacements were found to be around 6 and $1.5 \%$ for hinged and fixed end restraints, respectively.

Figure 19 illustrates the change in maximum soil surface displacements along with the change in soil suction that occurred within the active soil zone. The plot indicates a significant influence of the change in soil suction on the soil displacements. Maximum soil displacement was predicted to be about $80 \mathrm{~mm}$ at the ground surface, due to a total change in suction from 2000 to $38 \mathrm{kPa}$. The figure also shows the maximum upward displacements at the pipe level due to the same change in soil suction within the active zone at a relative depth ratio (DR) of 0.9. The maximum pipe displacement was found to be around $10 \mathrm{~mm}$, at a depth of $2.7 \mathrm{~m}$ below the surface.

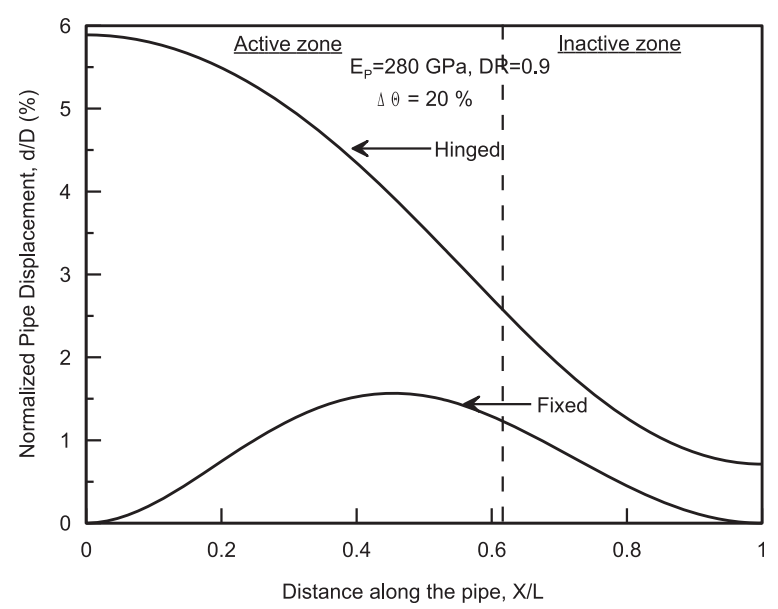

Fig. 18 Pipe displacements in case of hinged and fixed end restraints for a high elastic modulus magnitude (i.e. steel pipe) 


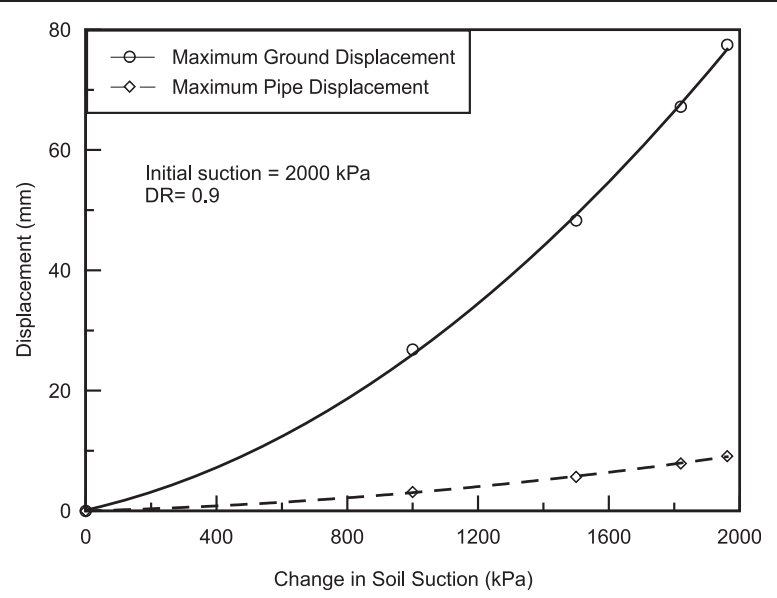

Fig. 19 Influence of the pipe burial depth on the pipe displacements

The results of the upward soil movement profiles can lead to an optimized pipe burial depth under the change in soil suction and at the selected factor of safety. Similarly, avoiding the excessive fluctuation in soil suction close to the area of the underground infrastructure may be an effective way for minimizing soil movements and resulting displacement of underground infrastructure.

\section{Summary of results}

The soil-pipe interaction of a typical buried pipeline configuration was studied by solving a set of stress-strain partial differential equations using a commercial finite element program FlexPDE. The proposed finite element modeling approach was established using the elastic continuum theory, considering volume change effects, soil layering, and displacement of the pipe in relation to the soil. The modeling approach provided reasonable results for the pipe deformations compared to design empirical equations. The key outcomes of this performance evaluation model can be summarized as follows:

- The geometric configuration of the pipe trench, including the cover height and trench width, significantly influenced the overall deformations of the soil-pipe system. Increased trench width along with enhanced soil conditions were found to provide more lateral support when the flexible pipe deforms. The effect of the field configuration, such as the trench width, in the calculation of pipe deformations was found to be essential for capturing the pipe deformations under field conditions.

- Flexible pipes are subjected to higher deformations due to their low stiffness. The pipe deformation was found to decrease with the increase in pipe diameter, and with the increase in the elastic modulus of backfill materials. This effect is a result of the improved confinement provided for the sides of the pipe.

The behavior of a buried pipe in unsaturated clay soil was modeled under saturation of the surrounding active layer. The adopted approach, through simulations of possible scenarios, provided better understanding of the field behavior of underground pipes. 
The pipe response was found to depend on the pipe depth, stiffness, and end restraints. The main results of this model can be summarized as follows:

- An increase in soil water content corresponding to a decrease in soil suction, resulted in significant upward displacements. The pipe displacements were highly influenced by pipe burial depth. The upward movements of pipelines can be notably reduced by a slight increase in burial depth.

- For the case study dealing with a pipe buried at a depth of $2.7 \mathrm{~m}$ (a relative depth ratio (DR) of 0.9 within the active soil zone):

o Maximum soil displacements at the ground and pipeline level were predicted to be about $80 \mathrm{~mm}$, and $10 \mathrm{~mm}$, respectively. This was a result of a total change in volumetric water content from $20 \%$ (close to the field condition) to $60 \%$ (close to the full saturation condition).

o Maximum pipe displacements of 2.1, 3.7, 5.3, and $6.0 \%$ were reported as results of the relative increase in volumetric water content of $5,10,15$, and $20 \%$, respectively.

- The end restraints of an underground flexible pipe (PVC pipe) affected the distribution of displacement along the pipeline but had a minimal influence on the maximum pipe displacement magnitude. However, the end restraints of an underground rigid pipe (i.e. steel pipe) affected the distribution and magnitude of displacement along the pipeline.

- In case of fixed end restraints and under the same change in moisture content of the soil, the maximum upward displacement of PVC pipes was found to be about four times the displacement of steel pipes.

\section{Conclusion}

It can be concluded that the use of highly plastic clay as a backfill material is not recommended for underground small diameter pipelines. In addition, it is highly recommended that the design guidelines of buried pipelines should take into consideration the volume change characteristics of the native soil deposits (specially for highly plastic clay soils) surrounding the pipe itself or the pipe trench in case of using a granular backfill material. One key criterion is to specify a minimum pipe depth below the ground surface for different pipe types in order to minimize the resulting soil swellshrink induced pipe displacements.

Competing interests

The authors declare that they have no competing interests.

Authors' contributions

RS carried out the numerical analysis and drafted the manuscript. Manuscript was checked and reviewed by $\mathrm{YH}$ and $\mathrm{AH}$. All authors read and approved the final manuscript.

\section{Acknowledgment}

The authors would like to acknowledge the National Research Council Centre for Sustainable Infrastructure Research for allowing access to their research facilities in order to conduct this research investigation.

Author details

${ }^{1}$ Environmental Systems Engineering, University of Regina, Regina, SK S4S OA2, Canada. ${ }^{2}$ AMEC Environment \& Infrastructure, Regina, SK S4N 4Y1, Canada. ${ }^{3} 2476$ Victoria Avenue, City of Regina, SK S4P 3C8, Canada. ${ }^{4}$ Faculty of Engineering and Applied Science, University of Regina, Regina, SK S4S OA2, Canada. 
References

ASCE (1984). Guidelines for the seismic design of oil and gas pipeline systems. ASCE Committee on Gas and Liquid Fuel Lifelines of the ASCE Technical Council on Lifeline Earthquake Engineering, New York, USA

AWWA Manual M23. (2002). PVC pipe-design and installation. USA: American Water Works Association.

Baracos, A, Hurst, WD, \& Legget, RF. (1955). Effects of physical on cast iron pipe. Journal of the American Water Works Association, 42, 1195-1206.

Barbato, M, Bowman, M, \& Herbin, A. (2010). Performance of buried pipe installation. USA: Report No. FHWA/LA.10/467, the U.S Department of Transportation, Federal Highway Administration, LTRC Project No. 08-6GT, State Project No. 739-99-1520.

Chen, L. (1990). Developments in Geotechnical Engineering Vol. 7: Limit analysis and soil plasticity. Amesterdam, The Netherlands: Elsevier Publishing.

Clark, CM. (1971). Expansive-soil effect on buried pipe. Journal of the American Water Works Association, 63, 424-427.

Clayton, CRI, Xu, M, Whiter, JT, Ham, A, \& Rust, M. (2010). Stresses in cast-iron pipes due to seasonal shrink-swell of clay soils. Proceedings of the ICE-Water Management, 163(WM3), 157-162.

Colasanti, RJ, \& Horvath, JS. (2010). A practical subgrade model for improved soil-structure interaction analysis: software implementation. Practice periodical on structural design and construction. American Society of Civil Engineers, 15(4), 278-286.

Dutta, SC, \& Roy, R. (2002). A critical review on idealization and modeling for interaction among soil-foundationstructure system. Computer and structures, 80, 1579-1594.

Eagle, JM (2009). Depth of Burial for PVC Pipe. J-M Manufacturing Company Inc. Technical Bulletin, http://www.jmeagle. com/pdfs/Technical\%20Bulletins/TB06DepthofBurialforPVC.pdf. Accessed 26 March 2014.

Fredlund, DG, \& Gitirana, JG. (2005). Unsaturated Soil Mechanics as a Series of Partial Differential Equations", Proc. International Conference on Problematic Soils, 25-27 May 2005 (pp. 1-28). Famagusta, N. Cyprus: Eastern Mediterranean University,

Fredlund, DG, \& Morgenstern, NR. (1976). Constitutive relations for volume change in unsaturated soils. Canadian Geotechnical Journal, 13(3), 261-276.

Fredlund, DG, \& Rahardjo, H. (1993). Soil Mechanics for Unsaturated Soils. New York: Wiley.

Fredlund, DG, \& Vu, HQ. (2003). Numerical modelling of swelling and shrinking soils around slabs on ground. Huntington Beach, CA, USA: Proc. Post-Tensioning Institute Annual Technical Conference.

Gould, S. (2011). A study of the failure of buried reticulation pipes in reactive soils, Ph.D Dissertation. Australia: Civil Engineering, Monash University.

Gould, S, Boulaire, F, Marlow, D, \& Kodikara, J. (2009). Understanding how the Australian climate can affect pipe failure. Melbourne, Australia: Proc. OzWater 09.

$\mathrm{Hu}, \mathrm{Y}, \& \mathrm{Vu}, \mathrm{QH}$. (2011). Analysis of soil conditions and pipe behaviour at a field site. Canadian Geotechnical Journal, $48(6), 847-866$.

Hudak, PF, Sadler, B, \& Hunter, BA. (1998). Analyzing underground water-pipe breaks in residual soils. Water Engineering and Management, 145, 15-20.

Klar, A, Vorster, TEB, Soga, K, \& Mair, RJ. (2004). Soil-pipe-tunnel interaction: comparison between Winkler and Elastic continuum solutions. Cambridge: Technical Report of the University of Cambridge CUED/D-SOILS/TR 332.

Marston, A, \& Anderson, AO. (1913). The theory of loads on pipes in ditches and tests of cement and clay drain tile and sewer pipe. Ames: lowa Engineering Experiment Station.

McGrath, TJ. (1998). Pipe-soil interactions during backfill placement, Ph.D. Thesis. Amherst, MA: University of Massachusetts.

Mordak, J, \& Wheeler, J. (1988). Deterioration of asbestos cement water mains. Final report to the Department of the Environment. Wiltshire, UK: Water Research Center.

Morris, RE. (1967). Principal causes and remedies of water main breaks. Journal of the American Water Works Association, 54, 782-798.

Moser, AP. (1990). Buried pipe design. New York, USA: McGraw-Hill.

Newport, R. (1981). Factors influencing the occurrence of bursts in iron water mains. Water Supply and Management, 3 , $274-278$.

Ng, PCF. (1994). Behavior of buried pipelines subjected to external loading, PhD Dissertation. Sheffield, U.K.: University of Sheffield

PDE Solutions Inc. (2006). FlexPDE6 reference manual. California, USA: PDE Solutions Inc.

Pentland, G, Gitirana, JG, Fredlund, DG (2001). Use of a general partial differential equation solver for solution of mass and heat transfer problems in geotechnical engineering. Proc. 4th Brazilian Symposium on Unsaturated Soils, Porto Alegre, RS, Brazil, 22 - 24 March, 29-45.

Rajani, B, \& Tesfamariam, S. (2004). Uncoupled axial, flexural, and circumferential pipe-soil interaction analyses of jointed water mains. Canadian Geotechnical Journal, 41, 997-1010.

Rajani, B, Zhan, C, \& Kuraoka, S. (1996). Pipe-soil interaction analysis for jointed water mains. Canadian Geotechnical Journal, 33(3), 393-404.

Rajeev, P, \& Kodikara, J. (2011). Numerical analysis of an experimental pipe buried in swelling soil. Computers and Geotechnics, 38(7), 897-904.

Rajeev, P, Chan, D, \& Kodikara, J. (2012). Ground-atmosphere interaction modelling for long-term prediction of soil moisture and temperature. Canadian Geotechnical Journal, 49, 1059-1073.

Robert, D, \& Soga, K. (2013). Soil-pipeline interaction in unsaturated soils. Mechanics of Unsaturated Geomaterials, 13, 303-325.

Saadeldin, R, Hu, Y, \& Henni, A. (2013a). Evaluation of the performance of buried pipes under different soil and loading conditions. Montreal, Canada: Proc. GeoMontreal 2013.

Saadeldin, R, Hu, Y, Siddiqua, S, \& Henni, A. (2013b). Response of buried pipes to unsaturated soil conditions. Fort Worth, TX, USA.: Proc. ASCE Pipelines. 
Spangler, MG. (1941). The design of flexible pipe culverts. Ames, lowa: lowa State College, Bulletin 153.

Trickey, S, \& Moore, I. (2007). Three-dimensional response of buried pipes under circular surface loading. Journal of Geotechnical and Geoenvironmetal Engineering, 133(2), 219-223.

Uni-Bell PVC Pipe Association. (2001). Handbook of PVC Pipe: design and construction. Texas, USA: Uni-Bell PVC Pipe Association

Vu, HQ, \& Fredlund, DG. (2004). The prediction of one-, two-, and three dimensional heave in expansive soils. Canadian Geotechnical Journal, 41, 713-737.

$\mathrm{Vu}, \mathrm{HQ}, \mathrm{Hu}, \mathrm{Y}$, \& Fredlund, DG. (2007). Analysis of soil suction changes in expansive Regina clay. Ottawa, ON, Canada: Proc. 60th Canadian Geotechnical Conference and 8th Joint IAH-CGS Conference.

Wijewickreme, D. (2012). Role of Geotechnical engineering in assuring the integrity of buried pipeline systems. Kandy, Sri Lanka: Proc. International Conference on Sustainable Built Environments.

Winkler, E (1867). The theory of elasticity and strength. Czechoslovakia: Dominicus, Prague (In German).

Zarghamee, MS. (1986). Buried flexible pipe with nonuniform soil support. Journal of Transportation Engineering, American Society of Civil Engineers, 112(4), 400-415.

Zhan, C, \& Ranjani, B. (1997). Load transfer analyses of buried pipe in different backfills. Journal of Transportation Engineering, American Society of Civil Engineers, 123(6), 447-453.

Zhao, Q, Kuraoka, S, Baker, THW, Masson, P, Gu, J-F, Boudreau, S, \& Brousseau, R. (1998). Durability and performance of gravity pipes: a state-of-the-art literature review. Ottawa, Canada: National Research Council of Canada, Urban Infrastructure Rehabilitation Program.

Submit your manuscript to a SpringerOpen ${ }^{\circ}$ journal and benefit from:

- Convenient online submission

- Rigorous peer review

- Immediate publication on acceptance

- Open access: articles freely available online

- High visibility within the field

- Retaining the copyright to your article

Submit your next manuscript at $>$ springeropen.com 